\title{
Laryngeal Paraganglioma
}

National Cancer Institute

\section{Source}

National Cancer Institute. Laryngeal Paraganglioma. NCI Thesaurus. Code C6409.

A benign or malignant extra-adrenal parasympathetic parag ang lioma arising from

parag ang lia adjacent to the larynx. Patients may present with hoarseness and dysphagia. 